\title{
Kicks Controlling Techniques Efficiency in Term of Time
}

\author{
Ali K. Darwesh, Thorkild Maack Rasmussen, Nadhir Al-Ansari \\ Department of Civil, Environmental and Natural Resources Engineering, Luleå University of Technology, Luleå, Sweden \\ Email: Ali.Darwesh@LTU.SE, Thorkild.Maack.Rasmussen@LTU.SE, Nadhir.alansari@LTU.SE
}

How to cite this paper: Darwesh, A.K., Rasmussen, T.M. and Al-Ansari, N. (2017) Kicks Controlling Techniques Efficiency in Term of Time. Engineering, 9, 482-492. https://doi.org/10.4236/eng.2017.95028

Received: May 3, 2017

Accepted: May 24, 2017

Published: May 27, 2017

Copyright (C) 2017 by authors and Scientific Research Publishing Inc. This work is licensed under the Creative Commons Attribution International License (CC BY 4.0).

http://creativecommons.org/licenses/by/4.0/ (c) (†) Open Access

\begin{abstract}
Kicks are the result of under balance drilling operation. Time consumed to control the kicks will be different in depending on the controlling technique. Drilling fluid considered as a first barrier to control formation pressure and well kicks. Any advance in drilling fluids leads to more controlled operation in term of time. This paper will follow the general increasing profile of pressure before entering the reservoir. Both methods of well controlling technique; circulating techniques and non-circulating have been implemented in many oil blocks. The process of designing and casing selection, setting depth and many other issues is predominately dependent on the utilization of accurate values of formation pressure. Formation pressures used to design safe mud weights to overcome fracturing the formation and prevent well kicks. Hence the emphasis has been placed on the practical utilization of kicks pressure near the reservoir. The presented relationships will help the engineer to better understand lithological columns and reduce potential hole problems during the kick appearance. Selecting the best well controlling practical method can lead to not harming the reservoir and more production later. Changes in some drilling fluid properties have been proposed with increasing the depth without damaging the reservoir. Suggestions in relation to the casing setting point of the intermediate section are also proposed. Standard equations with proper modification for gases and safety margin have been proposed for the future drilling operation in oil fields above the reservoir.
\end{abstract}

\section{Keywords}

Driller Technique, Engineer Technique, Drilling Fluid, Kicks, Reservoir

\section{Introduction}

A simple definition of the kicks is unscheduled entry of formation fluid(s) into the wellbore [1]. This will happen because the pressure inside the wellbore is 
lower than the formation pore pressure (in a permeable formation). Kicks can lead to what called blow out of the well if not controlled in time manner operation [2]. Over all kicks can happen when there will be disturbs to the pressure balance between the hydrostatic pressure of our drilling mud and the formation pressure. A kick or blowout may result from one of the following [3]:

1) Mud weight less than formation pore pressure

2) Failure to keep the hole full while tripping

3) Swabbing while tripping

4) Lost circulation

5) Mud cut by gas, water or oil

The ability of the industry to predict formation pressures has improved in recent years and is sophisticated [4]. While in some cases, the mud weight requirements are not known for some intervals to control kicks. Kurdistan was a closed area for oil investments in past before 1991. After 2003 many exploration oil wells have been drilled in more than 52 oil blocks that have been awarded to oil operators [5]. There were and still a use of very high and latest techniques to predict pore pressure while drilling, but still controlling the BHP and well kicks an important subject with challenge. Well control circulating techniques were the first and most proper responses to changes in formation pressures. Circulating well control techniques include driller's method, wait and weight, concurrent and reverse circulation.

Advances in well controlling systems came to appear in term of non-circulating well control techniques like volumetric method (Lubricate and Bleed) and Bullheading methods [3]. Well control methods aim to safely control the change in BHP and eliminating all their negative effects on the drilling operation. Circulating and none circulating well control methods are often referred to as "constant bottom hole" methods as they keep Bottom Hole Pressure (BHP) equal or little higher than Formation Pressure (FP) preventing additional influx of fluids that leads to kicks.

All methods in circulating technique use the same procedures and only differ when and if a kill weight fluid will be circulated [6]. In general, most of the wells cannot be killed by one circulation due to inefficient fluid displacement in the annulus, for that the operation timing is almost important.

BHP and surface pressures may be a combination of several types of pressure like Formation Pressure (FP), Hydrostatic Pressure (HP), circulating friction pressure and choke pressure [7]. Since FP, HP and circulating friction are fairly constant during the initial stages of well control; the only way to change pressure is by choke manipulation. Decreasing the pressures will be by opening the choke orifice size slightly and closing the choke orifice size to increase pressures. Choke adjustments must be made to maintain proper circulating pressure. The choke adjustments depend on the frictional properties of different fluids that are circulating especially the viscosity and the density [3]. If these parameters are changed, a drastic change in choke pressure can occur. Such is the case when gas begins to exit across the choke. 
A "rule of thumb" of two seconds per 1000 feet of well length is typically required to transit a pressure pulse in a drilling fluid as a lag time. So, lag time will increase with the depth. This point is very important if additional adjustments are made on the choke. Accurate and proper documentation is a very important aspect during the well control [8]. Recorded data will prevent any confusion about the pressures changes than to rely on memory. Offset data and newly records can be much valuable with the increase of the number of the drilled wells in the same block or nearby.

\section{Well Control Techniques}

In general they are two groups, circulating and none circulating techniques. Figure 1 shows the most popular kick control methods. During the kick appearances, the first step will be shutting the well in and start inspect if there are any leaks in BOP/manifolds, etc. Second step will be recording the Static Initial Drill Pipe Pressure (SIDPP), Static Initial casing Pipe Pressure (SICP) until pressures stabilize and record pit gain. The third step obviously depends on the killing method that the decision has been made on. Then circulation will start with holding choke (casing) pressure at its SICP value and SLOWLY bring pump up to Kill Rate Speed. Once pump is at kill speed, and casing pressure is at its SICP value, we have to record the circulating (pump) pressure. This pressure is called the Initial Circulating Pressure, ICP and must be held until the kill fluid will be pumped.

- $\quad \mathrm{ICP}=\mathrm{SIDPP}+\mathrm{KRP}$

$\mathrm{ICP}=$ initial circulating pressure $(\mathrm{psi})$

SIDPP $=$ Static Initial Drill Pipe Pressure (psi)

$\mathrm{KRP}=$ Killing Rate Pressure (psi)

This ICP will be the needed pressure to circulate a well at a given rate and prevent the well from flowing or kicking [7]. In case of this value does not agree with calculated values a quick decision must be made on the shutting pressure if it is correct or not or could be inaccurate due to gas migration. Gauges and pump efficiency also must be inspected weather they are working correctly or not or sometimes our calculations are not right. Try again if there were any shortages starting with shutting in the well.

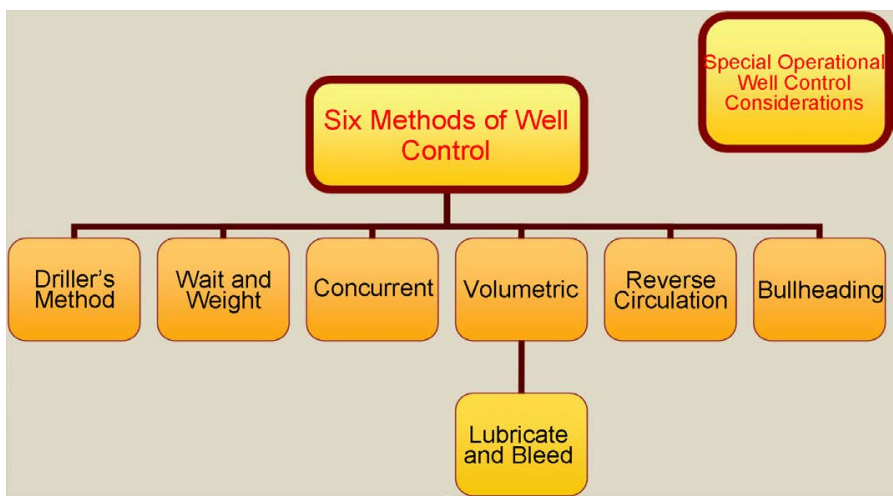

Figure 1. Well control techniques [9]. 


\section{Used Techniques}

Three well control techniques have been used during the operation of the case study, which they were:

1) Driller's Method

When there will be an indication of the kicks the driller starts to use this method as a first response. It is easy to implement and can be used to control wells with high migration rates that may result in shut-in well problems [9]. This method is also useful when there will some limitation on site to our operation like no enough weighting material, personnel and/or equipment.

2) Wait and Weight (Engineer) Method

This method kills the kick faster and keeps wellbore and surface pressures lower than any other method [3]. This method gives better results compared with the driller method with needs of good mixing facilities and drilling crews. Calculation of the killing fluid density will be the first work then circulating that killing mud. For that this method called Wait and Weight or Engineer method.

3) Volumetric Method of Well Control

It is the way of allowing controlled expansion of gas during migration. It replaces volume with pressure (or vice versa) to maintain BHP is equal to, or a little higher than FP. This method will be used to control the well until a circulating method can be implemented. Volumetric methods can be used in situations like plugged string, string is out of the hole, or pumps are not working and many other situations [7]. One of the basic scientific principles must be understood before using the volumetric method is Boyle's Law-shows the pressure/volume relationship for gas. It states that if gas can expand, pressure within the gas will decrease. This is the same concept used by the volumetric method in that it allows gas to expand by bleeding off an estimated fluid volume at surface, which results in decreasing of wellbore pressures.

P1 V1 = P2 V2 Boyle's Law

\section{Kurdistan Operations}

After 2003 many oil blocks have been awarded to the oil companies to start their investments. Up to date than 50 oil blocks have been awarded to oil operators in Kurdistan, north of Iraq Figure 2 shows some oil blocks that have been awarded [10]. One of these blocks is Bazian block. Bazian (Bn-1) was the first exploration oil well that was spudded in 2009 and finished in 2010.

\section{Data Collections}

Bn-1 was the first exploration oil well in Bazian block, in general the area were closed and there were no helpful offset data in relate to the FP or FG [12]. During the drilling operation there were a restrict instruction on data collection. A lot of data have been recorded, but the most important used data in this paper were drilling data, survey data and mud data Figure 3 show an example of some data in one figure. Size and length of all the drilled sections are figured in Figure 4 and Table 1. 


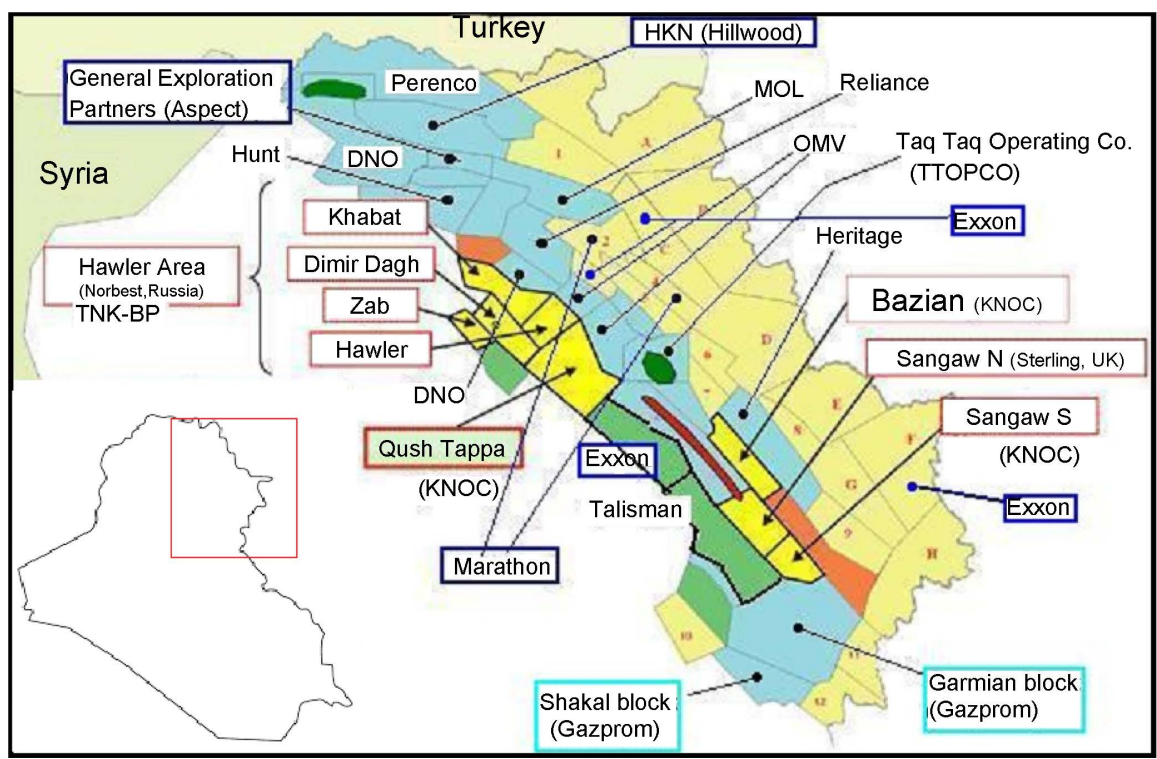

Figure 2. Oil blocks in Kurdistan region-Iraq [11].
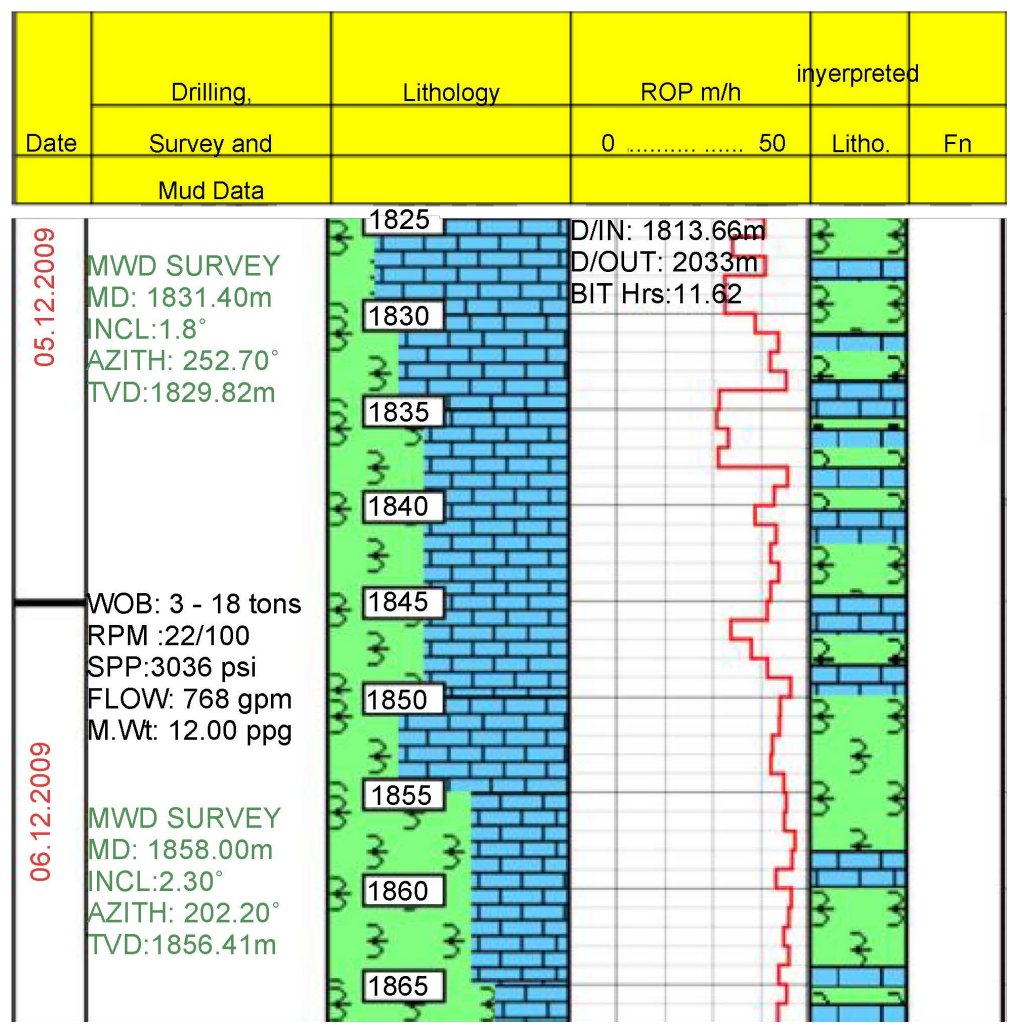

Figure 3. Drilling, survey and mud data [13].

Beside all the above collected data there were an accurate calculations for pore pressure for different penetrated geological formations till the target which was in Qamchuqa formation as it is clear in Table 2 below.

\section{Well Control Operation}

Here we study and discuss the drilling operation to control the well kicks in term 


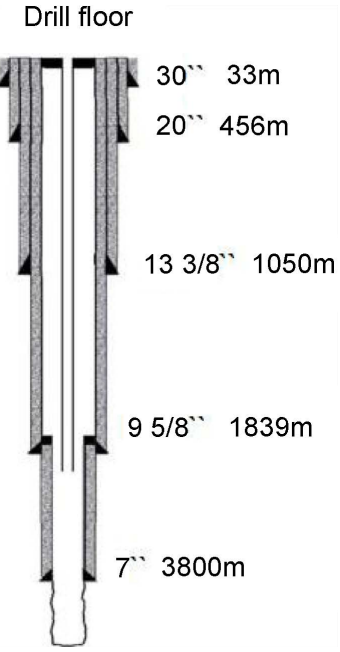

Figure 4. Drilled sections in Bn-1.

Table 1. Drilled sections data [12].

\begin{tabular}{|c|c|c|c|c|c|c|c|c|}
\hline & & & & CAS & NG DA & & & \\
\hline LOT: 1 & $5.7 \mathrm{ppg}$ & @ MD & & Ct ROD Te & 31 Tan & 010 & Next BOP Test is & 21.Feb.10 \\
\hline $1839 \mathrm{~m}$ & a/TVD & $837 \mathrm{~m}$ & & st DUP 1 est & 31.jan. & 010 & Next Casing Test & 21.Feb.10 \\
\hline OD (in) & ID (in) & $\mathrm{MD}(\mathrm{m})$ & TVD (m) & WT (Ib/ft & Grade & urst (Psi) & Collapse (Psi) & Tensile (kIbs) \\
\hline 30 & 27 & 17.5 & 17.5 & 453.15 & $\mathrm{X} 52$ & & & \\
\hline 20 & 18.73 & 467 & 467 & 133 & K55 & 3060 & 1493 & 2100 \\
\hline $133 / 8$ & 12.415 & 1196 & 1196 & 68 & L80 & 5020 & 2260 & 1556 \\
\hline $95 / 8$ & 8.861 & 1839 & 1837 & 47 & L80 & 6870 & 4760 & 1086 \\
\hline
\end{tabular}

Table 2. Calculated pore pressure Bn-1.

\begin{tabular}{cccc}
\hline Formation & Depth (m) TVD RTE & Pore Pressure (ppg) EMW & Temperature (C) \\
\hline Gercus & $137.5-246$ & $8.3-8.6$ & $38-40$ \\
Khurmala & $246-330$ & 8.6 & $40-42$ \\
Sinjar & $330-440$ & 8.6 & $42-45$ \\
Kolosh & $440-710$ & 8.6 & $45-51$ \\
Aliji & $710-1673$ & 8.6 & $51-72$ \\
Upper Shiranish & $1673-1943$ & 8.6 & $72-78$ \\
Lower Shiranish & $1943-2279$ & 8.6 & $78-86$ \\
Kometan & $2279-2376$ & 8.6 & $86-88$ \\
Qamchuqa/Sarmord & $2376-3635$ & $8.6-9.1$ & $88-116$ \\
Qamchuqa/Sarmord & $3635-3803$ & $10.2-10.7$ & $116-121$ \\
\hline
\end{tabular}

of time in $\mathrm{Bn}-1$ as a case study. During the drilling operation, there was a lot of time spend to control the BHP. The total of about 5 days with a full operation was spent to control the well. Similar scenario or worse happened in many other oil blocks in Kurdistan. There was an indication of Loss of Circulation (LOC) in the upper part of the production section after $2800 \mathrm{~m}$ and then kicks during the 
sliding drilling from $3630 \mathrm{~m}$ down. First pumping of Loss Circulating Materials (LCM) was at the upper part of the production section as a reaction of LOC. After that was an increase in pit volume up to $10 \mathrm{bbls}$ [13]. The normal standard action was shut-in the well and monitoring the pressure started.

Seven circulation stages with different mud properties and pumping a lot of LCM to control LOC the well was not controlled totally. The main changes were in the mud density starting from $8.6 \mathrm{ppg}$ and going to reach $12.1 \mathrm{ppg}$ at the seventh circulation stage during the implementation of Driller Technique. Engineer and Volumetric Techniques also have been implemented to control the well. Figures 5-7 show some stages of circulation to control the well with the first kick control technique.

Figure 5 shows all the seven circulations starting from 8:25 February 12, 2010, as we can observe that the pressure are going to fluctuate with a very big difference in drill pipe pressure and casing pressure. Circulation No. 7 was the last attempt in use of Driller method but still there is no certain confidence that the well have been controlled.

As can be seen there were two problems at the same time loss of circulation and kicks. This situation has been shown in the Figure 6 in yellow color we still

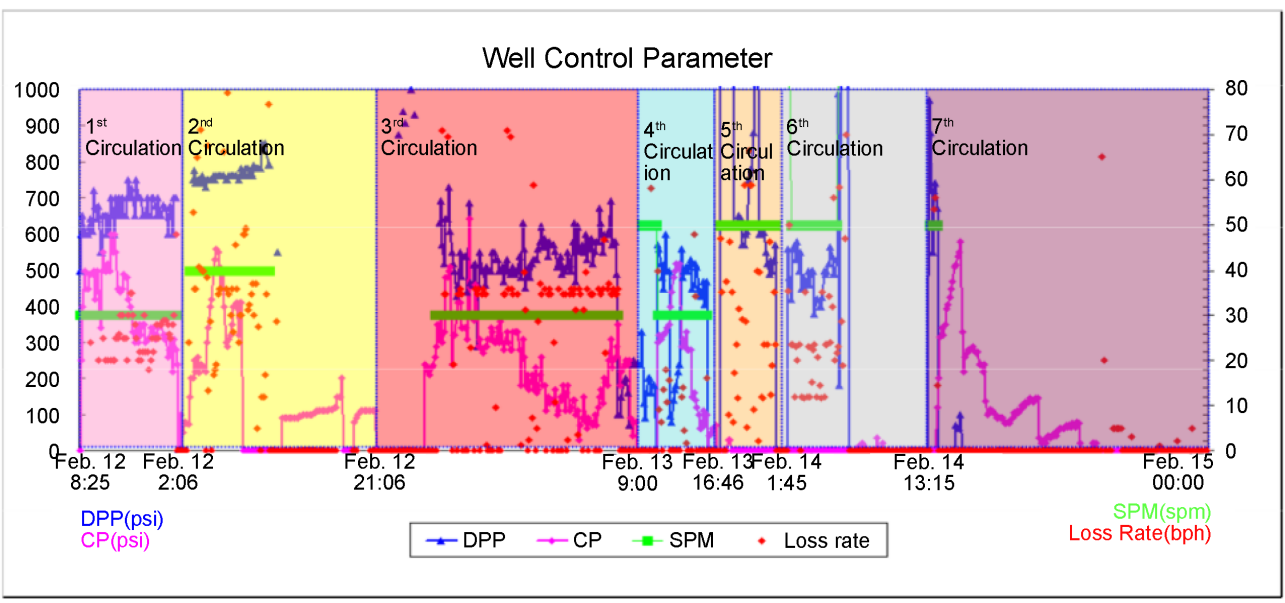

Figure 5. Summary of seven circulations attempt to control the kicks with Driller method.

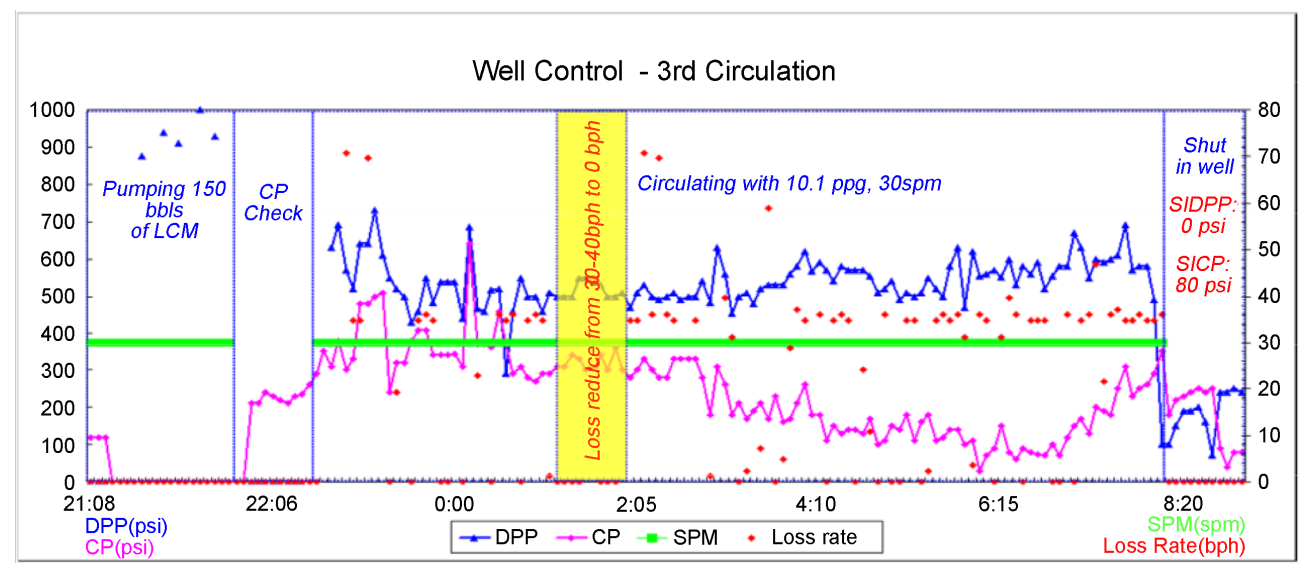

Figure 6. Circulations No. 3 in attempt to control the kicks with Driller method. 
there is some loss.

Directly after the Driller Method, Volumetric Methods were implemented starting with increasing the mud density from $9.3 \mathrm{ppg}$ to $12.1 \mathrm{ppg}$ to control the well and reach the situation of SIDPP and SICP to be zero psi [12]. Changes in the drill pipe pressure and casing pressure during February 15 and 16, 2010 for about 30 hours are shown in Figure 8 and Figure 9.

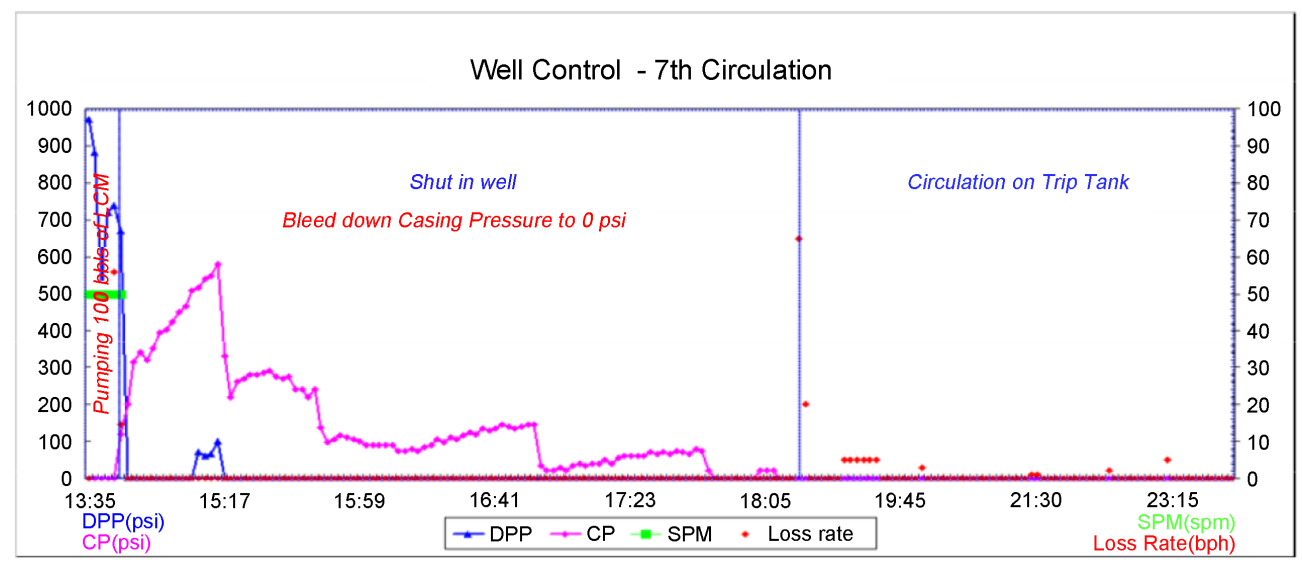

Figure 7. Circulations No. 7 in attempt to control the kicks with Driller method.

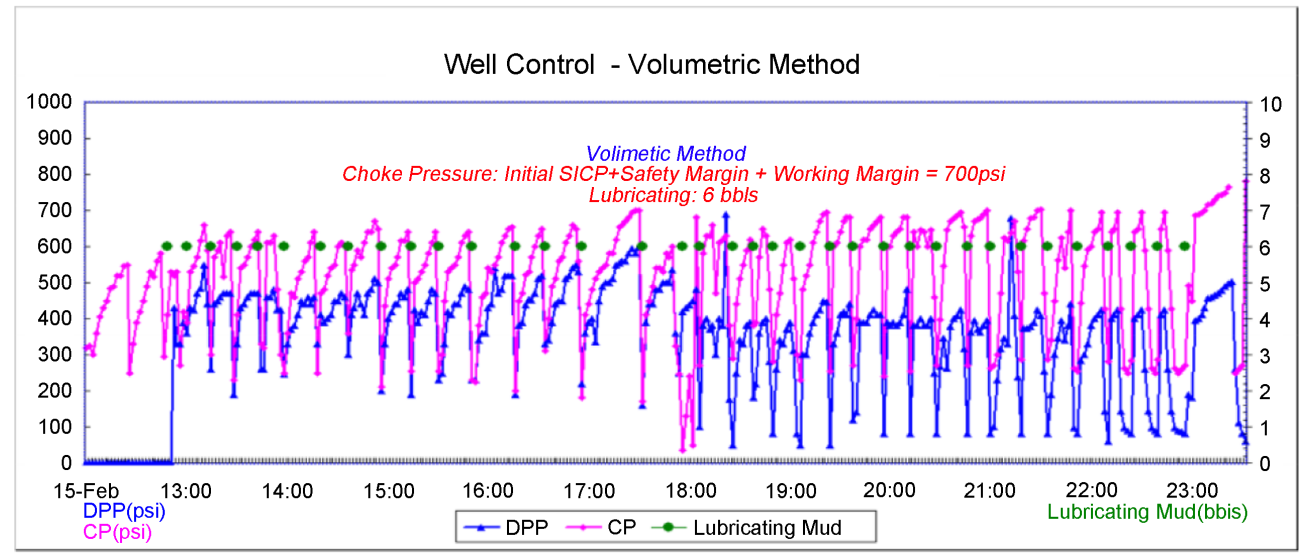

Figure 8. Volumetric attempt to control the kicks.

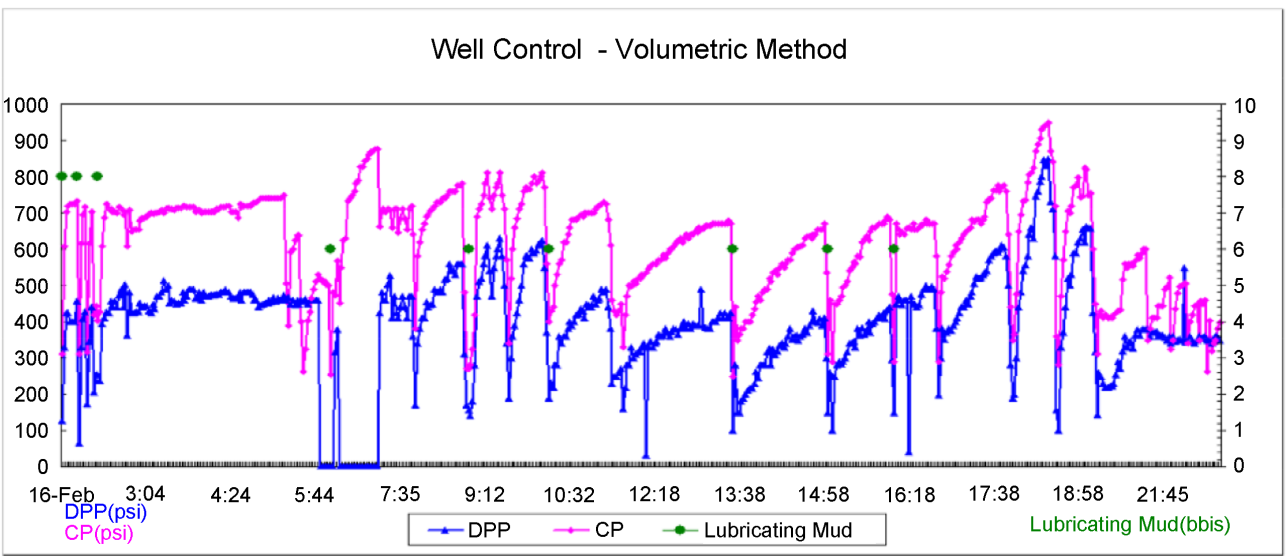

Figure 9. Volumetric attempt to control the kicks. 
The process of well controlling took 5 days and this was a high cost and increased the Non-Production Time (NPT) also. Table 3 shows the total time spent in different well control techniques to control the kicks.

\section{Discussion}

Driller's Method was first implemented in the case study well. The crew proceeded immediately to displace the gas influx. The required calculations were made on the kill-weight. Circulating the kill mud was not easily displaced and the drilling operation was resumed very slowly. One of the most disadvantages of the Driller's Method is that at least two circulations are required to control the well. In our case there were seven circulations which took a lot of time. After Driller method there were a decision to start implementing the Wait and Weight (Engineer Method) which is slightly more complicated but offers some distinct advantages. The most main advantages of the Engineer Method are the well will be killed in half the time [3]. The use modern mud-mixing facilities permit barite to be mixed at high rates, to make the time required to weight up the suction is minimized and kill rate reached quickly in the term of the time. The primary disadvantage in this method is the potential for errors and problems while displacing the kill-weight mud to the bit [9]. In Driller's Method, the procedure can be stopped and started easily. While stopping and starting when using the Wait and Weight Method (Engineer Method) is not as easy, especially during the period that the kill-weight mud is being displaced to the bit. With taking all considerations, the Wait and Weight Method is the preferred technique compared with the driller method.

Here in Bn-1 different controlling method have been used due to uncertainty about which one is the most suitable one. Within upper part of the near the Pay Zone Interval there were LOC and within the lower part there were kick problem. Any improvements on the drilling fluid properties give different results on upper and lower part of the section.

\section{Conclusions}

There are many well controlling methods; each has its advantages or disadvantages in a particular location or drilling operation situation. In our case study extending the setting point of the production casing pipes to deeper setting point between $2300 \mathrm{~m}$ to $2500 \mathrm{~m}$ in Shiranish formation will isolate the problematic interval more and more. Application of the Wait and Weight Method may even

Table 3. Time spend to control the kicks.

\begin{tabular}{cccc}
\hline Kick Control Method & Date (From) & Date (To) & Total Hours \\
\hline Driller Method & 11, Feb. 2010 & 13, Feb. 2010 & 51 \\
Wait and Wait & 13, Feb. 2010 & 15, Feb. 2010 & 47 \\
Volumetric & 15, Feb. 2010 & 16, Feb. 2010 & 31
\end{tabular}

129 hours $^{*}$ 
give us higher shoe pressures if the drill pipe pressure schedule is not calculated and followed properly.

Drilling near the target zone and the liner section in Shiranish formation with new mud system of liner increase of density, viscosity and gel strength makes the drilling operation more free problematic operation. Most of the times there will be difficulty in following properly some methods like W\&W. The Driller's Method is not also a preferred method all the times. Drilling the near pay zone interval with increased mud density, viscosity and gel strength without waiting for kick indication will result in saving more time and cost. Drilling long intervals with different geological properties above the target makes the kick controlling more difficult. Any decrease in NPT means more production and optimized operation economically. Any decrease in NPT means more friendly environmental operation in the area in term of pollution.

\section{Future Operations}

Avoid using one fluid system in drilling loss interval and pressured interval together. Using the Driller Method with implementing the equation of hydrostatic pressure plus a safety margin of 500 psi will serve the operation of drilling in term of time above the target. This means that Pore pressure $(\mathrm{Pp})$ will be:

$$
\text { Pp }=0.052 * \text { density } * \text { Depth }+500
$$

\section{References}

[1] Gatlin, C. (1960) Drilling and Well Completions. Department of Petroleum Engineering, University of Texas, Texas.

[2] Bourgoyne Jr., A.T., Chenevert, M.E., Milheim, K.K. and Young Jr., F.S. (1986) Applied Drilling Engineering. Society of Petroleum Engineers, Richardson.

[3] Grace, R.D. (1994) Advanced Blowout \& Well Control. Gulf Professional Publishing, Houston.

[4] Eckel, J.R. (1967) Microbit Studies of the Effect of Fluid Properties and Hydraulics on Drilling Rate. Journal of Canadian Petroleum Technology, 19, 541-546. https://doi.org/10.2118/1520-PA

[5] ShaMaran (2012) Total to Acquire ShaMaran Taza Oil Field in Kurdistan. https://www.2b1stconsulting.com/total-in-the-race-to-kurdistan-with-exxonmobiland-chevron/

[6] Wardlaw, H. (1969) Drilling Performance Optimization and Identification of Overpressure Formations. Society of Petroleum Engineers, Richardson. https://doi.org/10.2118/2388-ms

[7] Rabia, H. (2002) Well Engineering \& Construction. Entrac Consulting Limited, London.

[8] Fear, M. (1999) How to Improve Rate of Penetration in Field Operations. SPE Drilling \& Completion, 14, 42-49. https://doi.org/10.2118/55050-PA

[9] Wild Well (2016) Well Control Methods http://www.wildwell.com/literature-on-demand/literature/well-control-methods.pdf

[10] Darwesh, A. (2014) RIH Intermediate Section Casing in Bazian-1 Exploration Oil Well. WIT Transactions on Ecology and the Environment, 186, 559-669. https://doi.org/10.2495/esus140491 
[11] Alan131210 (2011) Kurdistan Oil \& Gas Development. https://northerniraq.info/forums/viewtopic.php? $\mathrm{t}=5889$

[12] Korean National Oil Corporation, KNOC (2009) Daily Drilling Reports (Drilling Report No. 3). KNOC, Kurdistan.

[13] Korea National Oil Corporation, KNOC (2009) MLU Data (No. MLOG 0-627). KNOC, Kurdistan.

Submit or recommend next manuscript to SCIRP and we will provide best service for you:

Accepting pre-submission inquiries through Email, Facebook, LinkedIn, Twitter, etc. A wide selection of journals (inclusive of 9 subjects, more than 200 journals)

Providing 24-hour high-quality service

User-friendly online submission system

Fair and swift peer-review system

Efficient typesetting and proofreading procedure

Display of the result of downloads and visits, as well as the number of cited articles

Maximum dissemination of your research work

Submit your manuscript at: http://papersubmission.scirp.org/

Or contact eng@scirp.org 